\title{
The (mis)measurement of the Dark Triad Dirty Dozen: Exploitation at the core of the scale
}

Petri J Kajonius, Björn N Persson, Patricia Rosenberg, Danilo Garcia

Background: The dark side of human character has been conceptualized in the Dark Triad Model: Machiavellianism, psychopathy, and narcissism. These three dark traits are often measured using single long instruments for each one of the traits. Nevertheless, there is a necessity of short and valid personality measures in psychological research. As an independent research group, we replicated the factor structure, convergent validity and item response for one of the most recent and widely used short measures to operationalize these malevolent traits, namely, Jonason's Dark Triad Dirty Dozen. We aimed to expand the understanding of what the Dirty Dozen really captures because the mixed results on construct validity in previous research.

Method: We used the largest sample to date to respond to the Dirty Dozen $(N=3,698)$. We firstly investigated the factor structure using Confirmatory Factor Analysis and an exploratory distribution analysis of the items in the Dirty Dozen. Secondly, using a subsample $(n=500)$ and correlation analyses, we investigated the Dirty Dozen dark traits convergent validity to Machiavellianism measured by the Mach-IV, psychopathy measured by Eysenck's Personality Questionnaire Revised, narcissism using the Narcissism Personality Inventory, and both neuroticism and extraversion from the Eysenck's questionnaire. Finally, besides these Classic Test Theory analyses, we analyzed the responses for each Dirty Dozen item using Item Response Theory (IRT).

Results: The results confirmed previous findings of a bi-factor model fit: one latent core dark trait and three dark traits. All three Dirty Dozen traits had a striking bi-modal distribution, which might indicate unconcealed social undesirability with the items. The three Dirty Dozen traits did converge too, although not strongly, with the contiguous single Dark Triad scales ( $r$ between .41-.49). The probabilities of filling out steps on the Dirty Dozen narcissism-items were much higher than on the Dirty Dozen items for Machiavellianism and psychopathy. Overall, the Dirty Dozen instrument delivered the most predictive value with persons with average and high Dark Triad traits (theta $>-0.5$ ). Moreover, the Dirty Dozen scale was better conceptualized as a combined 
Machiavellianism-psychopathy factor, not narcissism, and is well captured with item 4: '। tend to exploit others towards my own end'.

Conclusion: The Dirty Dozen showed a consistent factor structure, a relatively convergent validity similar to that found in earlier studies. Narcissism measured using the Dirty Dozen, however, did not contribute with information to the core of the Dirty Dozen construct. More importantly, the results imply that the core of the Dirty Dozen scale, a manipulative and anti-social trait, can be measured by a Single Item Dirty Dark Triad (SIDDT). 
9 The (mis)measurement of the Dark Triad Dirty Dozen: Exploitation at the core of the scale ${ }^{1}$ Department of Psychology, University of Gothenburg, Gothenburg, Sweden ${ }^{2}$ Department of Social Psychology, University of Skövde, Skövde, Sweden ${ }^{3}$ Network for Empowerment and Well-Being, Gothenburg, Sweden 
Background: The dark side of human character has been conceptualized in the Dark Triad Model: Machiavellianism, psychopathy, and narcissism. These three dark traits are often measured using single long instruments for each one of the traits. Nevertheless, there is a necessity of short and valid personality measures in psychological research. As an independent research group, we replicated the factor structure, convergent validity and item response for one of the most recent and widely used short measures to operationalize these malevolent traits, namely, Jonason's Dark Triad Dirty Dozen. We aimed to expand the understanding of what the Dirty Dozen really captures because the mixed results on construct validity in previous research.

Method: We used the largest sample to date to respond to the Dirty Dozen $(N=3,698)$. We firstly investigated the factor structure using Confirmatory Factor Analysis and an exploratory distribution analysis of the items in the Dirty Dozen. Secondly, using a sub-sample $(n=500)$ and correlation analyses, we investigated the Dirty Dozen dark traits convergent validity to Machiavellianism measured by the Mach-IV, psychopathy measured by Eysenck's Personality Questionnaire Revised, narcissism using the Narcissism Personality Inventory, and both neuroticism and extraversion from the Eysenck's questionnaire. Finally, besides these Classic Test Theory analyses, we analyzed the responses for each Dirty Dozen item using Item Response Theory (IRT).

Results: The results confirmed previous findings of a bi-factor model fit: one latent core dark trait and three dark traits. All three Dirty Dozen traits had a striking bi-modal distribution, which might indicate unconcealed social undesirability with the items. The three Dirty Dozen traits did converge too, although not strongly, with the contiguous single Dark Triad scales ( $r$ between .41.49). The probabilities of filling out steps on the Dirty Dozen narcissism-items were much higher than on the Dirty Dozen items for Machiavellianism and psychopathy. Overall, the Dirty Dozen instrument delivered the most predictive value with persons with average and high Dark Triad traits (theta $>-0.5$ ). Moreover, the Dirty Dozen scale was better conceptualized as a combined Machiavellianism-psychopathy factor, not narcissism, and is well captured with item 4: 'I tend to exploit others towards my own end'.

Conclusion: The Dirty Dozen showed a consistent factor structure, a relatively convergent validity similar to that found in earlier studies. Narcissism measured using the Dirty Dozen, however, did not contribute with information to the core of the Dirty Dozen construct. More importantly, the results imply that the core of the Dirty Dozen scale, a manipulative and antisocial trait, can be measured by a Single Item Dirty Dark Triad (SIDDT). 
69

70 "Show me again, the power of the darkness, and I'll let nothing stand in our way. Show me, 71 grandfather, and I will finish what you started. “

72 From Star Wars: The Force Awakens

73 Over the last 25 years, the vast majority of personality research has focused on the Big Five traits: openness, conscientiousness, extraversion, agreeableness, and neuroticism. The Big Five Model of personality is a theory developed from both language taxonomy as well as statistical factor analysis (Costa \& McCrae, 1992). Critics have argued against - what they believe is - the overreliance on factor analysis (i.e., one of the methods in Classical Test Theory) to uncover the latent structure of personality, without a well-grounded theoretical basis and substantial variation in methodology (e.g., Block, 1995; Gould, 1981). In the last decade, personality psychologists have turned their attention to the dark side of human character: Machiavellianism, psychopathy, and narcissism. Together, these traits are widely known as the Dark Triad model (Paulhus \& Williams, 2002). The validation studies of Dark Triad measures have mostly been conducted using Classic Test Theory methods and in very few cases using Item Response Theory (IRT) methods. Generally speaking, the Dark Triad embodies interpersonal, sub-clinical, and maladaptive personality traits in the general population (Paulhus \& Williams, 2002), which are characterized by manipulativeness (i.e., Machiavellianism), impulsivity and antagonism (i.e., psychopathy), and the sense of entitlement (i.e., narcissism). The Dark Triad traits are associated with a value system of unconventional and antisocial morality (Kajonius, Persson, \& Jonason, 2015; for a more extensive review see Furnham, Richards, \& Paulhus, 2013 and Paulhus, 2014). In essence, individuals with high levels on any of these dark traits appear to operate in selfish and competitive ways with a common core of uncooperativeness (see Jones \& Figueredo, 2013). Thus, whether the dark traits constitute a ternary model of unique traits or a unified 
93 uncooperative general factor with three closely related anti-social sub-traits is still a question for

94 research. In this context, validation studies using IRT methods might shed some light on what

95 different measures of the Dark Triad actually measure.

96 As with most personality psychology research, the measurement of individuals' tendencies

97 on the dark traits is often conducted using self-report measures. Most of the time, this has been

98 done using one instrument for each trait. These single instruments are often long and time

99 demanding. For the trait of Machiavellianism, for example, researchers often use Christie and

100 Geis' Mach-IV (1970), which was originally based on statements from the Italian Niccolò

101 Machiavelli's books The Prince and The Discourse (see also Jones \& Paulhus, 2009, who point

102 out that the instrument also captures behaviors from the Chinese military general, strategist, and

103 philosopher Sun Tzu's book The Art of War; behaviors such as planning, building a reputation,

104 and creating alliances). The trait of psychopathy is often measured with the Self-report

105 Psychopathy Scale (Hare, 1985). This instrument was first used on prisoners and later on 106 validated in non-criminal populations as well (Hare, 1985). Nevertheless, also the psychoticism

107 scale in the hierarchical three-factor model proposed by Eysenck (e.g., Eysenck, Eysenck, \&

108 Barrett 1985) has, even though not without criticism, been used as a measure of psychopathy in

109 terms of "Impulsive Unsocialized Sensation Seeking" (Zuckerman, Kuhlman, Thornquist, \&

110 Kiers, 1991. See also Zuckerman, 1989, 1991; Linton \& Power, 2013; Garcia \& Sikström, 2014).

111 Finally, narcissism is often measured using the Narcissism Personality Inventory, which

112 comprises 80 (long version) or 32 (short version) paired-items (Raskin \& Hall, 1979). More

113 recently, shorter measures comprising all three traits in one single instrument have been created

114 to facilitate data collection. 
115 One such measure is the Dark Triad Dirty Dozen (Jonason \& Webster, 2010). See Table

1161 for the statements and the key word in each one of the statements in the Dirty Dozen scale. The

117 Dirty Dozen comprises 12 items that in four consecutive studies were demonstrated to retain its

118 core of disagreeableness when compared to 91 items from questionnaires that measured the dark

119 traits separately (Jonason \& Webster, 2010). This is a reduced item count by $87 \%$. Subsequent

120 studies with smaller samples have explored the thin line between efficiency and accuracy in this

121 short scale. The findings suggest that a bi-factor structural model with both a general latent Dark

122 Triad construct and the three dark traits of Machiavellianism, psychopathy, and narcissism best

123 fit the data. In addition, the findings also show relatively good convergent validity with the

124 Mach-IV $(r=.53)$, the Self-report Psychopathy Scale III $(r=.32)$, and the Narcissism

125 Personality Inventory-40 $(r=.53)$ (Jonason \& Luévano, 2013). Further validations, using a

126 sample of young undergraduates, were reported with the ubiquitous Big Five Inventory

127 developed by Benet-Martínez and John (1998). The findings revealed an unstable core of

128 conscientiousness for psychopathy and agreeableness for both Machiavellianism and

129 psychopathy, with no clear relationships with extraversion for narcissism (Jonason,

130 Kaufman,Webster, \& Geher, 2013). Again, a bi-factor model (i.e., one general factor plus three

131 specific factors) fitted the data best. This suggests that each dark trait measured something

132 unique (Jonason, Kaufman, Webster, \& Geher, 2013), in addition to the common variance

133 captured by the general factor. However, criticism has also been leveled against the Dirty Dozen.

134 For instance, the Dirty Dozen's incremental, discriminant, and convergent validity has been

135 called into question when compared with other relevant measures (Jones \& Paulhus, 2014;

136 Maples, Lamkin, \& Miller, 2014; Miller et al., 2012). Additionally, its construct validity has

137 been disputed, as using merely 4 items (per factor) may remove essential content (Miller et al., 
138 2012). In addition to validations using Classical Test Theory current research for validation of

139 Dark Triad scales has used IRT models.

140

142

144

145

146

147

148

149

150

151

152

153

154

155

156

157

Table 1 should be here

There is a large diversity of models that have been developed using IRT. IRT was first

proposed in the field of psychometrics for the purpose of ability assessment. For instance, all major educational tests are developed using this technique because it significantly improves measurement accuracy and reliability, and it provides significant reductions in assessment time and effort (for a review see An \& Yung, 2014). In recent years, this technique has also been applied in health and clinical research (e.g., Hays, Morales, \& Reise, 2000; Edelen \& Reeve, 2007; Holman, Glas, \& de Haan, 2003; Reise \& Waller, 2009). Using IRT models, researchers have found a slightly lower endorsement threshold of the dark traits for males compared to females. This has been interpreted as differences in social undesirability sensitivity, or true differences as proposed by mating-strategy theory (Webster \& Jonason, 2013). The latest validation study among onsite UK undergraduates and online Crowdflower-workers ${ }^{1}$, however, found conflicting results using Mokken analysis, a non-parametric form of IRT (Carter, Campbell, Muncer, \& Carter, 2015). While the expected three traits of Machiavellianism, psychopathy, and narcissism, emerged among female students' scores; only two traits emerged among male students' scores. These two traits were a combined Machiavellianism-psychopathy factor and a narcissism factor. In contrast, among the online workers, only one core construct of the Dirty Dozen appeared. These differences were not explained by invariance over sex and age.

\footnotetext{
1 "CrowdFlower is a data enrichment, data mining and crowdsourcing company based in the Mission District of San Francisco, California. The company's software as a service platform allows users to access an online workforce of millions of people to clean, label and enrich data. CrowdFlower is typically used by data scientists at academic institutions, start-ups and large enterprises."

Retrieved from: https://en.wikipedia.org/wiki/CrowdFlower.
} 
158 Hence, this casts some uncertainty on the evasive constructs measured by the Dirty Dozen scale

159 or suggests some kind of mismeasurement of the triad by this specific scale.

160 The Present Study

161 The possibility to replicate findings is one of the parameters that distinguish science from non-

162 science. In short, replication should be at "the heart of science" (Schmidt, 2009). By use of

163 conceptual replications we can potentially confirm which findings about human nature that can

164 be generalized and thus increase predictive validity in our regular use of psychological

165 measurements. As researchers we expect that replication studies are common and that the

166 methodology is well developed, however, particularly in social sciences the contrary is true,

167 demonstrating an overall replication rate of only 1.07\% (Makel, Plucker, \& Hegarty, 2012; see

168 also Lucas \& Donnellan, 2013, and the Registered Replication Reports initiative by the

169 Association for Psychological Science,

170 http://www.psychologicalscience.org/index.php/replication).

171 A major problem in current validations is the small sample sizes and a general lack of

172 power and precision. This "results in lower precision in parameter estimates and systematically

173 inflated effect size estimates" (Lucas \& Donnellan, 2013, p. 453). In addition, the current

174 validation studies that have been published provide many statistically significant low-powered

175 findings even within the same study, which "paradoxically provide less support for a

176 phenomenon than papers that report some failures to reach statistical significance" (Lucas \&

177 Donnellan, 2013, p. 453; see also Francis, 2012; Schimmack, 2012). To the best of our

178 knowledge, the present study provides the largest single sample used to this date $(N=3,698)$ to

179 replicate some of the most common findings with regard to the Dirty Dozen scale. For instance,

180 previous validation studies on the Dirty Dozen have had limited, or at least unclear, 
181 generalizability, often only including undergraduates or homogenous age cohorts. In addition,

182 although we do believe in researchers' capacity for objectivity, we see as an important venue that

183 an independent research group that had no ties to the construction of the Dirty Dozen scale

184 conducted the present replication study.

185 First, we used Confirmative Factor Analysis (CFA) to investigate the original factor

186 structure of the Dirty Dozen, which has shown varied results in previous studies, this time using

187 a sizable, heterogeneous sample from all walks and ages of life. In addition, with the large

188 sample at hand, there were sufficient respondents for an exploratory distribution analysis, which

189 has not been reported before. Second, we further establish the validity of the traits measured

190 using the Dirty Dozen by investigating convergence with known, contiguous single long scales

191 of the dark traits: the Mach-IV, Eysenck's Personality Questionnaire Revised, and the

192 Narcissism Personality Inventory. Third, using IRT, we explored what the Dirty Dozen

193 endeavors to measure. We propose that what makes the Dark Triad, measured by this specific

194 scale, "dark" may not be a uniform stable core but, instead, a challenging mix of malevolent and

195 tradition-laden anti-social and uncooperative traits. If so, we might be able to clarify what the

196 Dirty Dozen measures and uncover what scale-items might be responsible for the many

197 interpretations of its core.

198

Method

199 Ethical statement

200 After consulting with the Network for Empowerment and Well-Being's Review Board we

201 arrived at the conclusion that the design of the present study (e.g., all participants' data were

202 anonymous and will not be used for commercial or other non-scientific purposes) required only

203 informed consent from the participants. 


\section{Participants}

205 The participant data was collected through Mechanical Turk (MTurk), which has demonstrated

206 reliability and validity, providing a wider range of socio-economic backgrounds compared to

207 other samples (Casler, Bickel, \& Hackett, 2013). This is particularly useful when it comes to

208 research on values, such as the undesirability of the Dark Triad traits' values (cf. Kajonius et al.,

209 2015). All participants were informed that the survey was voluntary, anonymous, and that the

210 participants could terminate the survey at any time. The MTurk workers received 50 cents (US-

211 dollars) as compensation for participating and only residents of the US were allowed to accept

212 participation. Two control questions were added to the survey, to control for automatic responses

213 (e.g., "This is a control question, please answer "neither agree or disagree"). A total of 50

214 participants responded erroneously to one or both of the control questions, the final sample

215 constituted 3,698 $\left(M_{\text {age }}=33.5, S D=11.8\right)$. As expected, males $\left(N_{\text {males }}=1,726\right)$ scored higher on

216 all Dark Triad traits than females $\left(N_{\text {females }}=1,972\right)$, as summarized in the descriptive Table 2 . A

217 subsample $(N=500)$ also answered to single long instruments of the Dark Triad, extraversion, 218 and neuroticism.

Table 2 should be here

\section{Measures}

The Dark Triad Dirty Dozen (Jonason \& Webster, 2010) is a 12-item self-report

questionnaire measurement of the three Dark Triad traits. Participants are asked to rate how

much they agreed $(1=$ Strongly disagree; 7 = Strongly agree $)$ with statements such as: "I tend to manipulate others to get my way" (Machiavellianism), "I tend to lack remorse" (psychopathy),

225 and "I tend to want others to admire me" (narcissism). Items were averaged to create each 226 dimension (Cronbach's alphas between .74 to .85; see Table 2 for alphas for both males and 
227 females). We also constructed a composite score of the three dark traits by using the mean values 228 from all of the items. ${ }^{2}$ For facilitating readability, all measures of the dark traits using the Dirty

229 Dozen are labeled as follows: DD Machiavellianism, DD psychopathy, and DD narcissism. High

230 scores represent high degree in each of the dark traits or, in the case of the composite, a high

231 degree of the Dark Triad Dirty Dozen core.The Mach-IV (Christie \& Geis, 1970) was used to

232 also measure Machiavellianism. The Mach-IV consists of 20 items that reflect ways of thinking

233 and opinions about people and different situations (e.g., "Never tell anyone the real reason you

234 did something unless it is useful to do so"). Participants were requested to rate to what extent

235 they agree with each statement on a 6-point Likert scale: $1=$ Strongly agree, $6=$ Strongly

236 disagree. The Machiavellianism score was computed by summarizing the means across the 20

237 items, a high score representing high degree of Machiavellianism.

238 The short version of the Eysenck's Personality Questionnaire Revised was used to

239 measure extraversion (e.g., "Do you usually take the initiative in making new friends?"),

240 neuroticism (e.g., "Do you ever feel 'just miserable' for no reason?"), and psychoticism (e.g.,

241 "Would you like other people to be afraid of you?") (Eysenck, Eysenck, \& Barrett, 1985). The

242 Eysenck questionnaire consists of 12 items for each trait (forced binary answers: Yes or No). The

243 score for each of the personality traits was computed as the sum of the 12 items, with yes

244 responses coded as 1 and no responses coded as 0 . Thus, a high score represents high degree in

245 each of the three personality traits. As stated in the Introduction section, Eysenck's psychoticism

246 scale has, however imperfectly, been suggested as partly tapping into the sensation-

\footnotetext{
${ }^{2}$ We are well aware of the controversy concerning composite scores present in the literature (e.g., Glenn \& Sellbom, 2015). While we're inclined to agree with their arguments on a theoretical level, we've elected to use a composite score as it is a quick abbreviation of a general "dark personality". Furthermore, we conducted an exploratory omega analysis (function omega in R package psych, see also Revelle \& Wilt, 2013), which yielded a $\omega_{\text {hierarchical }}$ coefficient of .72, which suggests that the Dirty Dozen is saturated by a general factor. Additionally, the correlation between the composite score and an unrotated principal component was .994. This also serves as rationale for utilizing a unidimensional IRT model (see Ip, 2010). These analyses are available from the corresponding author upon request.
} 
247 seeking/boldness part of psychopathy (cf. Zuckerman, 1989, 1991). For the rest of the paper we

248 refer to the psychoticism scale as psychopathy.

249 The short version of the Narcissistic Personality Inventory was used to also measure

250 Narcissism (Ames, Rose \& Anderson, 2006). The instrument consists of 16 pairs of items (one

251 consistent and one inconsistent with narcissistic behavior in each pair) for what participants are

252 instructed to choose, for each pair, one item that comes closest to describing their own feelings

253 and beliefs about themselves. The narcissism score was computed as the sum of the 16 items,

254 with narcissism-consistent responses (e.g., "I really like to be the center of attention") coded as 1

255 and narcissism-inconsistent responses coded as 0 (e.g., "It makes me uncomfortable to be the

256 center of attention"). Thus, a high score represents high degree of narcissism.

\section{Statistical Analysis}

258 As in earlier studies, there was a relatively large skewness in the psychopathy scores and kurtosis

259 in the narcissism scores. This has, however, been shown to not have a negative effect on

260 subsequent statistical analysis when the sample size reaches the thousands (Lumley, Diehr,

261 Emerson, \& Chen, 2002). First, using Classic Test Theory, we used CFA for testing two

262 contending models, one with only the latent dark triad core branching into three dark traits, and

263 second, a bi-factor model with the latent dark triad core connecting directly with all items, while

264 the three dark traits connecting only to their respective items. We used Structural Equation

265 Modeling (SEM) in the software Amos version 22 for these calculations. In addition, we

266 conducted an exploratory distribution analysis using the large sample at hand. Second, using the

267 subsample, we conducted convergent correlational analyses in SPSS version 22 with the

268 collected contiguous single dark traits scales and Extraversion and Neuroticism (i.e., Mach-IV,

269 Eysenck's Personality Questionnaire Revised, and the Narcissism Personality Inventory). Third, 
270 using the large sample and with the purpose of exploring the Dirty Dozen content, we utilized

271 the much in-demand method of IRT using the R package MIRT version 1.10 (Chalmers, 2012) in

$272 \mathrm{R}$ version 3.2.1 ( $\mathrm{R}$ Core Team, 2015). This is a methodology for modeling how test items

273 contribute to one latent, scalable trait. We used a graded response model analogous to the two-

274 parameter model for dichotomous items, which basically generates two defining characteristics

275 for each item: a slope coefficient, or discrimination parameter alpha $(a)$, and a discrimination

276 coefficient, or threshold parameter beta $(b)$. The $a$ parameter shows how strongly an item relates

277 to a given latent construct theta $(\theta$; which in this study the Dark Triad core as measured by the

278 Dirty Dozen scale). The $a$ parameter can be analogized as a factor loading, whereas the threshold

279 parameters $b_{1-6}$ relates to the level of the latent trait at which the next highest response category

280 has at least $50 \%$ probability of being endorsed. For more information about IRT see Morizot, 281 Ainsworth, and Reise (2007).

\section{Results}

283 The first purpose was to replicate the original factor-structure of the Dirty Dozen using Classic

284 Test Theory. Two CFA-models were tested. The first model, a hierarchical structure, with the

285 Dark Triad core "above" the three dark traits, DD Machiavellianism $(\lambda=.75)$, DD psychopathy

$286(\lambda=.86)$, and DD narcissism $(\lambda=.56)$, was not optimal $\left(\chi^{2}(40)=1530.24, p<.001\right)$ and with non-

287 satisfactory fit indices as well $(\mathrm{NFI}=.92, \mathrm{CFI}=.92$, and $\mathrm{RMSEA}=.10)$. The second model

288 tested was a bi-factor structure, which proved more successful $\left(\chi^{2}(28)=360.19, \mathrm{p}<.01\right)$ with

289 sufficient fit indices $(\mathrm{NFI}=.98, \mathrm{CFI}=.98$, and RMSEA $=.05)$. The RMSEA of this specific

290 model was slightly better than in previous studies (RMSEA $=.07$ in Jonason \& Luévano, 2013;

291 RMSEA $=.06$ in Jonason et al., 2013). Furthermore, our model showed that 3 out of the 4 items

292 in the DD narcissism cluster had very weak relationships with the Dark Triad core and that the 
293 DD Machiavellianism-items demonstrated the strongest relationships. The full model with all

294 items' regression coefficients is reported in Figure 1.

295

296

297

298

299

300

301

302

303

304

305

306

307

308

309

310

311 show relatively weak (all $r \mathrm{~s}<.50$ ) converging relationships (Machiavellianism $r=.49$;

312 psychopathy $r=.41$, narcissism $r=.47$ ). That is, the three dark traits measured with Dirty Dozen

313 showed that DD Machiavellianism and DD psychopathy showed similar correlations, while DD

314 narcissism related less well with the corresponding scales measured using the single long scales.

315 Additionally, the Dirty Dozen Dark Triad composite (Table 3, row 4) showed the smaller 
316 relationships with the dark traits measured using the single long scales (correlations between the

317 Dirty Dozen dark traits and the Dark Triad core were between .75-.88, correlations between the

318 dark traits measured with the single instruments and the Dark Triad core were between .31-53).

319 In addition, there are some discrepancies between the correlations between neuroticism and

320 extraversion and the dark traits depending on how the Dark Triad was measured. For example,

321 while there was a weak significantly positive correlation between DD narcissism and neuroticism

$322(r=.20, \mathrm{p}<.01)$, there was no significant correlation to neuroticism when narcissism was

323 measured using the Narcissism Personality Inventory $(r=-.07)$. In contrast the relationship

324 between narcissism and extraversion was almost twice as large when narcissism was measured

325 using the single instrument $(r=.40, p<.01)$ than when measured using the Dirty Dozen $(r=.25$, $326 p<.01)$.

The third and last purpose was to extend the discussion on the construct of the Dark Triad as measured by the Dirty Dozen scale, using IRT. The results from both the CFA model 1 (NFI = $.92)$ and $2(\mathrm{NFI}=.98)$ indicated adequate unidimensionality, which is the basic assumption for

331 IRT. We ran a polytomous graded-response model on the 12 Dirty Dozen items, allowing items

332 to load on a latent Dark Triad core. The Total Information Curve reported in Figure 3 shows that

333 the core of the Dark Triad $(\theta)$ was revealed in a maximized way only when a participant has

334 close to average levels $(-0.5)$ of this latent trait (see Figure 4 for the Information Curve for each 335 one of the dark traits measured using the Dirty Dozen). Hence, the Dirty Dozen scale functions

336 well for capturing average and higher levels of the core Dark Triad, but not the lower levels. This

337 once again leads to the question what constitutes the dark core, or more specifically to what the 
338 Dirty Dozen scale actually measures. See Figure 5 for Scale Information Curves and Table 4 for

339 Item Response Theory Rank and Exploratory Factor Analysis of the Dirty Dozen Items.

340

341

342

343

344

345

346

347

348

349

350

351

352

353

354

355

356

357

358

359

360
Figure 3 should be here

Figure 4 should be here

Figure 5 should be here

Table 4 should be here

In Table 5 the items' ability to differentiate ( $a$ parameter) between people with similar

levels of the same latent trait are ranked, starting with the item yielding the most information (item 4: Exploit). The a-parameter typically ranges from 0.5 to 2.0 in personality scales (Morizot, Ainsworth, \& Reise, 2007). As can be seen, three of the four DD narcissism items (item 10: Attend, item 9: Admire, and item 11: Status) contributed least to differentiation between individuals. The difficulties $(b)$ for each item are listed in rows, and reflect the threshold levels of the latent trait necessary to have at least $50 \%$ chance of endorsing the next scale-step (e.g., $b_{1}$ denotes answering Option 1 vs. $2,3,4,5,6,7$ ). The $b$-parameters are scaled on the same metric as the latent trait $(\theta)$ and falls in the range of -3 to $+3 \mathrm{SD}$, thus 0 is approximated to be of average difficulty (at the mid-point of the distribution). At the highest scale-step $\left(b_{6}\right)$, all subfactor items showed extreme difficulty, close to $3 \mathrm{SD}$. At the lower end $\left(b_{1}\right)$, the items on DD Machiavellianism (items 1-4) and DD psychopathy (items 5-8), still showed much difficulty, close to average 0 , while narcissism (items 9-12), showed much less difficulty, close to -2SD. These results imply that DD narcissism is not contributing as much information to the core constitution of the dark triad construct, since the probability of filling out steps on the DD narcissism-items are much higher than on the DD Machiavellianism and DD psychopathy-items (cf. first, the skewness in distributions in Figure 2 and second, that DD narcissism correlated the 
361 least with the contiguous scales in Table 3). In other words, when a respondent does fill out high

362 numbers on scale-items on DD Machiavellianism and DD psychopathy, this rapidly predicts the

363 latent level of participant's core dark personality (e.g., item 1: Manipulate, $a=2.73$ or item 6:

364 Amoral, $a=1.91$ ), but not for DD narcissism (e.g., item 10: Attend, $a=.91$ ). The separate item

365 information curves are found in Figure 4.

366 The item with the highest $a$ (item 4: Exploit, $a=3.33$ ), was of particular interest, due to its

367 superior discriminatory ability compared to the others. We surmised that this item in itself would

368 be able to capture the entire Dark Triad core, as measured by the Dirty Dozen scale. This

369 exploitation-item correlated with the summed Dark Triad $(r=.77)$, to the same degree that the

370 three dark traits did, DD Machiavellianism $(r=.88)$, DD psychopathy $(r=.75)$, and DD

371 narcissism $(r=.76)$. When exchanging the summed Dark Triad for the single exploit-item, the

372 internal reliability between the constructs was only marginally lowered: inter-item .61 to .51;

373 Cronbach's alpha .85 to .80. Finally, comparing the single item with the convergence

374 coefficients of the summed Dark Triad composite (Table 3), the single item performed as well or

375 better as a substitute.

$\underline{\text { Table } 5 \text { should be here }}$

\section{Discussion}

378 This was a replication study of the popular and much used Dirty Dozen, based on the largest and

379 most diverse sample to date. All previous research results on the bi-factor structure and 380 convergent validity were confirmed. Concerning the previous varying findings on one-factor, bi-

381 factor, or three-factor solutions (cf. Carter et al., 2015), the large sample in the present study

382 warrants to overall lean towards a bi-factor solution. However, a new (or old) problem was

383 brought to the surface with the reporting of a strong bi-modal distribution of all three sub-factors, 
384 Machiavellianism, psychopathy, and narcissism. This has not been much emphasized in previous

385 publications and a contribution of the present study is to highlight the scope of this problem and

386 admonish for large samples sizes when researching the Dark Triad, which is known to

387 compensate for unwanted distribution skewness in statistical analyses (cf. Lumley et al., 2002).

388 In the wake of the Mokken analysis by Carter et al. (2015), one of the attempts of this

389 paper was to further the discussion on what the Dark Triad trait consists of and what the Dirty

390 Dozen seeks to measure. First, the distribution analyses (Figure 2) can be interpreted as an inertia

391 to filling out Machiavellianism- and psychopathy-items, while narcissism-items showed normal,

392 unskewed distribution, and consequently, not adding as much to the prediction of the core

393 construct. A second clue to the latent core of the Dark Triad is the convergence analysis in Table

3943 indicating that narcissism was the sub-factor that least correlated with the adjacent constructs

395 of sub-factors to Mach-IV and Eysenck's Personality Questionnaire, again showing that

396 Machiavellianism-psychopathy is at the center of the construct. Although the $r \mathrm{~s}$ in these

397 convergence validity analyses were relatively low, if the convergent validity between two

398 variables are modeled as loading on a latent 'true' variable, $r=.50$ would imply a whole $50 \%$

399 overlap (see Ozer, 1985; Trafimow, 2015). This could rightly be argued as a sufficient

400 convergent validity. That being said, it is important to mention that there is another brief measure

401 for assessment of the dark traits (i.e., the Short Dark Triad), which seems to perform better than

402 the Dirty Dozen scale (e.g., Jones \& Paulhus, 2014; Maples et al., 2014). In addition, although

403 we used convergent analyses as in many other validation studies; recent research suggests that

404 short scales should not be validated using these type of analysis (Olaru, Witthöft \& Wilhelm,

405 2015). Third, the IRT-analysis showed that narcissism-items (e.g., need for admiration, attention,

406 and status) had the least difficulty and the least discriminating power, not contributing to the total 
407 information on the latent dark trait. We conclude and submit for future research that the Dirty

408 Dozen is a measurement consisting of a core found in Machiavellianism-psychopathy (e.g.,

409 manipulation, deceit, amorality, and callousness, with no remorse, as seen in Table 5).

410 Our proposal is that the Dark Triad, at least as measured by the Dirty Dozen, might be the

411 product of a hasty grouping of two uncooperative sub-factors, Machiavellianism and

412 psychopathy, together with one "desirable” sub-factor, narcissism (see also Garcia \& Rosenberg,

413 2016). Being narcissistic is indeed considered more normal in these days and times (Twenge,

414 Campbell, \& Freeman, 2012), not as undesirable to fill out in questionnaires, and does not add to

415 the core of the construct. This suggests that grouping these three traits is unfortunate from both a 416 social desirability- (method artifact) and a subclinical perspective (how to find people with real

417 problems). If one wants to quickly find the core of the Dark Triad, a one-item of "I exploit 418 others" might be a suggestion. A similar approach has been taken recently with narcissism, 419 compressing the original 40-item scale into a Single Item Narcissism Scale (SINS), and 420 demonstrating reliability and validity in a number of studies (Konrath, Meier, \& Bushman, 2014; 421 van der Linden \& Rosenthal, 2015).

422

423

424 Limitations and Future Research

425 The convergent validity analyses were limited to the fact that, outside the Dark Triad we only 426 assessed extraversion and neuroticism. Both of these traits are related to affective experience and 427 attention to emotional cues (Lucas, 2008). The inclusion of traits such as agreeableness, openness, and conscientiousness could be useful in future studies. That being said, one possible reason to the mixed results in earlier research is that these personality traits used to find 
430 differences or similarities between people's dark character traits only represent individuals'

431 emotional reactions or temperament (e.g., McAdams, 2001; Haidt, 2006). After all, temperament

432 is not useful in the distinction of who ends up with a mature or immature character (Cloninger,

433 2004). Indeed, not all individuals who are extroverts end up scoring high in psychopathy and/or

434 narcissism (i.e., antecedent variables have different outcomes or "multi-finality") and high scores

435 in each one of the dark traits might have different antecedents (i.e., "equifinality")" (see

436 Cloninger \& Zohar, 2011). Recent studies, for instance have found that the Dark Triad is rather a

437 dyad when compared to Cloninger's ternary model of "light" character traits: self-directedness,

438 cooperativeness, and self-transcendence (Garcia \& Rosenberg, 2016). Specifically,

439 Machiavellianism and Psychopathy have a uncooperative and low self-directedness core, while

440 narcissism is positively associated to self-directedness.

441 Although it was explicitly stated in the Introduction and Method sections that

442 psychoticism, as measured in the Eysenck's model, is better understood as the psychopathy trait

443 in the Dark Triad, it is important to point out that most studies use other measures to

444 operationalize this trait (e.g., the Self-Report Psychopathy Scale-II and III by Levenson, Kiehl \&

445 Fitzpatrick, 1995, respectively Paulhus, Neumann \& Hare, in press). Nevertheless, other

446 researchers have also used the measure developed by Eysenck to operationalize psychopathy in

447 the Dark Triad (e.g., Linton \& Power, 2013).

448 The varying social undesirability with all sub-factors measured by the Dirty Dozen

449 should be further explored. It is not clear if the bi-modality of distribution is a reflection of this,

450 or if it is a certain group of people with for instance very high Big Five-agreeableness, thus

451 virtually hitting zero on all sub-factors of the Dirty Dozen. In other words, it is not clear if this

452 indicates a genuine difference in the Dark Triad as a construct that is not instrument-specific. 
453 Additional studies have to be carried out using different methods and measures in order to assess

454 whether or not such a difference is a method artifact or a real difference.

455 Another problem is that it is not apparent to what extent a short Dark Triad scale taps into 456 and is confounded by clinical populations. In a large replication study such as the present, 457 statistically $1-5 \%$ will be eligible for personality disorders. The results from IRT implicates that 458 item-difficulties are sufficient on Machiavellianism and psychopathy to be able to distinguish 459 problematic levels of the dark personality core, but not narcissism.

460 Conclusion

461 The conclusion on our part is that the Dirty Dozen has its advantages by being short, intuitive, 462 and even fun, containing high face validity, but also has drawbacks by being highly differing in 463 item-difficulties. The mismeasurement of the Dirty Dozen seems to be that it actually measures 464 two constructs, narcissism and an anti-social trait. This specific conclusion is supported by the 465 fact of what we choose to call a Single Item Dirty Dark Triad (SIDDT), the "exploit" item. In 466 situations of restrained research time and space, the SIDDT may capture the essence of what the 467 Dirty Dozen actually measures.

468

\section{References}

Ames, D. R., Rose, P., \& Anderson, C. P. (2006). The NPI-16 as a short measure of narcissism. Journal of Research in Personality, 40(4), 440-450.

471 An, X., \& Yung, Y-F. (2014). Item response theory: What it is and how you can use the IRT $472 \quad$ procedure to apply it. Paper SAS364-2014.

473 Benet-Martínez, V., \& John, O. P. (1998). Los cinco grandes across cultures and ethnic groups: 474 Multitrait multimethod analysis of the Big Five in Spanish and English. Journal of 475 Personality and Social Psychology, 75, 729-750. 
476 Block, J. (1995). A contrarian view of the five-factor approach to personality description. $477 \quad$ Psychological bulletin, 117(2), 187-215. doi:10.1037/0033-2909.117.2.187

478 Carter, G. L., Campbell, A. C., Muncer, S., \& Carter, K. A. (2015). A Mokken analysis of the 479 Dark Triad 'Dirty Dozen': Sex and age differences in scale structures, and issues with $480 \quad$ individual items. Personality and Individual Differences, 83, 185-191.

481 Casler, K., Bickel, L., \& Hackett, E. (2013). Separate but equal? A comparison of participants 482 and data gathered via Amazon's MTurk, social media, and face-to-face behavioral testing. 483 Computers in Human Behavior, 29(6), 2156-2160.

484 Chalmers, R. P. (2012). mirt: A multidimensional item response theory package for the R 485 environment. Journal of Statistical Software, 48(6), 1-29.

486 Christie, R., \& Geis, F. L. (1970). Studies in Machiavellianism. New York: Academic Press.

487 Cloninger, C. R. (2004). Feeling good: The science of well-being. New York: Oxford University $488 \quad$ Press.

489 Cloninger, C.R., \& Zohar, A.H (2011). Personality and the perception of health and happiness. $490 \quad$ Journal of Affect Disorder, 128(1-2): 24-32.

491 Costa, P. T., \& McCrae, R. R. (1992). Revised NEO personality inventory (NEO PI-R). Odessa, $492 \quad$ FL: Psychological Assessment Resources.

493 Edelen, M. O., \& Reeve, B. B. (2007). Applying item response theory (IRT) modeling to 494 questionnaire development, evaluation, and refinement. Quality of Life Research, 16(1), 5$495 \quad 18$.

496 Eysenck, S. B., Eysenck, H. J., \& Barrett, P. (1985). A revised version of the psychoticism scale. 497 Personality and Individual Differences, 6(1), 21-29. 
498 Francis, G. (2012). Too good to be true: Publication bias in two prominent studies from 499 experimental psychology. Psychonomic Bulletin \& Review, 19(2), 151-156.

500 Furnham, A., Richards, S.C., \& Paulhus, D. L. (2013). The Dark Triad of personality: A 10 year $501 \quad$ review. Social and Personality Psychology Compass, 7, 199-216.

502 Furnham, A., Richards, S., Rangel, L., \& Jones, D. N. (2014). Measuring malevolence: 503 Quantitative issues surrounding the Dark Triad of personality. Personality and Individual 504 Differences, 67, 114-121.

505 Garcia, D., \& Sikström, S. (2014). The dark side of Facebook: Semantic representations of status 506 updates predict the Dark Triad of personality. Personality and Individual Differences, 67, $507 \quad 92-96$

508 Garcia, D., \& Rosenberg, P. (2016). The Dark Cube: Dark and Light Character Profiles. PeerJ 509 4:e1675; DOI: 10.7717/peerj.1675.

510 Glenn, A. L., \& Sellbom, M. (2015). Theoretical and empirical concerns regarding the dark triad 511 as a construct. Journal of Personality Disorders, 29(3), 360-377.

512 Gould, S. J. (1981). The Mismeasure of Man. New York: W. W. Norton \& Company.

513 Haidt, J. (2006). The happiness hypothesis: Finding modern truth in ancient wisdom. New York: $514 \quad$ Basic Books.

515 Hare, R. D. (1985). Comparison of procedures for the assessment of psychopathy. Journal of $516 \quad$ Consulting and Clinical Psychology, 53(1), 7.

517 Hays, R. D., Morales, L. S., \& Reise, S. P. (2000). Item response theory and health outcomes 518 measurement in the 21st century. Medical Care, 38(9), II-28-II-42.

519 Holman, R., Glas, C. A., \& de Haan, R. J. (2003). Power analysis in randomized clinical trials 520 based on item response theory. Controlled Clinical Trials, 24(4), 390-410. 
521 Ip, E. H. (2010). Empirically indistinguishable multidimensional IRT and locally dependent 522 unidimensional item response models. British Journal of Mathematical and Statistical 523 Psychology, 63(2), 395-416.

524 Jonason, P. K., Kaufman, S. B., Webster, G. D., \& Geher, G. (2013). What Lies Beneath the 525 Dark Triad Dirty Dozen: Varied Relations with the Big Five. Individual Differences

Jonason, P. K., \& Luévano, V. X. (2013). Walking the thin line between efficiency and accuracy: Validity and structural properties of the Dirty Dozen. Personality and Individual Differences, 55(1), 76-81.

Jonason, P. K., \& Webster, G. D. (2010). The dirty dozen: a concise measure of the dark triad. Psychological Assessment, 22(2), 420-432.

Jones, D. N., \& Figueredo, A. J. (2013). The core of darkness: Uncovering the heart of the Dark Triad. European Journal of Personality, 27, 521-531.

534 Jones, D. N., \& Paulhus, D. L. (2009). Machiavellianism. In M. R. Leary \& R. H. Hoyle (Eds.), Handbook of individual differences in social behavior (pp. 93-108). New York, NY: Guilford Press.

Jones, D. N., \& Paulhus, D. L. (2014). Introducing the Short Dark Triad (SD3): A Brief Measure of Dark Personality Traits. Assessment, 21(1), 28-41.

Kajonius, P. J., Persson, B. N., \& Jonason, P. K. (2015). Hedonism, Achievement, and Power: Universal values that characterize the Dark Triad. Personality and Individual Differences, 77, 173-178.

542 Konrath S., Meier B. P., \& Bushman, B. J. (2014). Development and Validation of the Single Item Narcissism Scale (SINS). PLoS ONE, 9(8): e0103469. 
544 Levenson, M. R., Kiehl, K. A., \& Fitzpatrick, C. (1995). Assessing psychopathic attributes in a 545 noninstitutionalized population. Journal of Personality and Social Psychology, 68, 151$546 \quad 158$.

547 Linton, D. K., \& Power, J. L. (2013). The personality traits of workplace bullies are often shared 548 by their victims: Is there a dark side to victims. Personality and Individual Differences, 54, 738-743.

550

551

552

553

554

555

556

557

558

559

560

561

562

563

564

565

566

Lucas, R. E. (2008). Personality and Subjective Well-Being. In M. Eid, \& R.J. Larsen (Eds.). The science of subjective well-being (pp. 171-194). New York: The Guilford Press.

Lucas, R. E., \& Donnellan, M. B. (2013). Improving the replicability and reproducibility of research published in the Journal of Research in Personality. Journal of Research in Personality, 4(47), 453-454.

Lumley, T., Diehr, P., Emerson, S., \& Chen, L. (2002). The importance of the normality assumption in large public health data sets. Annual Review of Public Health, 23(1), 151169.

Makel, M. C., Plucker, J. A., \& Hegarty, B. (2012). Replications in psychology research how often do they really occur? Perspectives on Psychological Science, 7(6), 537-542.

Maples, J. L., Lamkin, J., \& Miller, J. D. (2014). A test of two brief measures of the dark triad: The dirty dozen and short dark triad. Psychological Assessment, 26(1), 326-331.

McAdams, D. P. (2001). The psychology of life stories. Review of General Psychology, 5, 100122.

Miller, J. D., Few, L. R., Seibert, L. A., Watts, A., Zeichner, A., \& Lynam, D. R. (2012). An examination of the Dirty Dozen measure of psychopathy: A cautionary tale about the costs of brief measures. Psychological Assessment, 24(4), 1048-1053. 
567 Morizot, J. M., Ainsworth, A. T., \& Reise, S. P. (2007). Towards modern psychometrics:

568 Application of item response theory models in personality research. In R. W. Robins, R. C.

$569 \quad$ Fraley, \& R. F. Krueger (Eds.), Handbook of research methods in personality psychology

570 (pp. 407-423). New York, NY: Guilford Press.

571 Olaru, G., Witthöft, M., \& Wilhelm, O. (2015). Methods Matter: Testing Competing Models for

572 Designing Short-scale Big-Five Assessments. Journal of Research in Personality, 59, 56-

$573 \quad 68$.

574 Ozer, D. J. (1985). Correlation and the coefficient of determination. Psychological Bulletin, $57597(2), 307-315$.

576 Paulhus, D. L. (2014). Toward a taxonomy of dark personalities. Current Directions in 577 Psychological Science, 23(6), 421-426.

578 Paulhus, D. L., Neumann, C. S., \& Hare, R. D. (in press). Manual for the Hare Self-Report 579 Psychopathy scale. Toronto, Ontario, Canada: Multi-Health Systems.

580 Paulhus, D. L. \& Williams, K. M. (2002). The Dark Triad of personality: narcissism, 581 Machiavellianism, and psychopathy. Journal of Research in Personality, 36, 556-563.

582 R Core Team (2015). R: A language and environment for statistical computing [computer 583 software]. R Foundation for Statistical Computing, Vienna, Austria.

584 Raskin, R. N., \& Hall, C. S. (1979). A narcissistic personality inventory. Psychological Reports, 585 45(2), 590-590.

Reise, S. P., \& Waller, N. G. (2009). Item response theory and clinical measurement. Annual 587 Review of Clinical Psychology, 5, 27-48.

588 Revelle, W., \& Wilt, J. (2013). The general factor of personality: A general critique. Journal of 589 Research in Personality, 47(5), 493-504. 
590 Schimmack, U. (2012). The ironic effect of significant results on the credibility of multiple-study $591 \quad$ articles. Psychological Methods, 17(4), 551.

592 Schmidt, S. (2009). Shall we really do it again? The powerful concept of replication is neglected 593 in the social sciences. Review of General Psychology, 13(2), 90-100.

594 Trafimow, D. (2015). The intelligibility of $\mathrm{r}$ or $\mathrm{r} 2$ as an effect size statistic: dichotomous 595 variables. Frontiers in Psychology, 6, 294.

596 Twenge, J. M., Campbell, W. K., \& Freeman, E. C. (2012). Generational differences in young 597 adults' life goals, concern for others, and civic orientation, 1966-2009. Journal of $598 \quad$ Personality and Social Psychology, 102, 1045-1062.

599 van der Linden, S., \& Rosenthal, S. A. (2015). Measuring narcissism with a single question? A 600 replication and extension of the Single-Item Narcissism Scale (SINS). Personality and $601 \quad$ Individual Differences, 90, 238-241.

602 Webster, G. D., \& Jonason, P. K. (2013). Putting the "IRT" in "Dirty": Item response theory 603 analyses of the Dark Triad Dirty Dozen-An efficient measure of narcissism, psychopathy, 604 and Machiavellianism. Personality and Individual Differences, 54(2), 302-306.

605 Zuckerman, M. (1989). Personality in the third dimension: A psychobiological approach. $606 \quad$ Personality and Individual Differences, 10(4), 391-418.

607 Zuckerman, M. (1991). Psychobiology of personality. Cambridge: Cambridge University Press.

608 Zuckerman, M., Kuhlman, D. M., Thornquist, M., \& Kiers, H. (1991). Five (or three) robust 609 questionnaire scale factors of personality without culture. Personality and Individual 610 Differences, 12(9), 929-941.

\section{Legends}


612 Table 1. Jonason's Dark Triad Dirty Dozen Scale: traits, item numbers, statements, and key word

613 in each one of the statements.

614 Note. From Jonason, P. K., \& Webster, G. D. (2010). The Dirty Dozen: A concise measure of the

615 Dark Triad. Psychological Assessment, 22, 420-432.

616

617 Table 2. Descriptive Analysis of the Dark Triad traits as measured by the Dark Triad Dirty 618 Dozen.

619 Note. $N=3,698 ; N_{\text {males }}=1726 ; N_{\text {females }}=1972 ;{ }^{+}$composite score of the three dark traits. 620

621 Table 3. Convergent analysis (Persons' r) of the Dark Triad Dirty Dozen traits and the dark traits 622 and Extraversion, and Neuroticism as measured by the Mach-IV, Eysenck's Personality 623 Questionnaire Revised, and the Neuroticism Personality Inventory.

624 Note. $\mathrm{N}=500$. All $\mathrm{r}$ coefficients $>.12$ are significant at $\mathrm{p}<.01$. + Summarized composite score 625 of the three dark traits.

626 Yellow fields: intra-relationships within the Dark Triad Dirty Dozen traits and the Dark Triad 627 composite.

628 Blue fields: intra-relationships within the Dark Triad traits measured by the single instruments 629 (i.e., MACH-IV, Eysenck's Personality Questionnaire Revised, and the Narcissism Personality 630 Inventory).

631 Green fields: relationships between corresponding dark traits measured using the Dirty Dozen 632 scale and the single instruments.

633 Black fields: relationships between dark traits as measured by the Dirty Dozen and Neuroticism 634 and Extraversion. 
635 Grey fields: relationships between dark traits as measured by the single instruments and 636 Neuroticism and Extraversion.

637

638 Table 4. Item Response Theory Rank and Exploratory Factor Analysis of Dirty Dozen Items.

639 Note. $^{*}=$ Potentially conflicting items in regards to double-loadings. Bold figures $=$ Loadings 640 according to three-factor Dark Triad theory. Cursive figures = Loadings deviating from three-

641 factor Dark Triad theory $(>.50)$. Item 8, underscored, "I tend to be cynical" does not load well 642 enough on the psychopathy-factor and deviates from theory by aligning also with 643 Machiavellianism (especially for females). Items 1, "I tend to manipulate others to get my way", 644 4, "I tend to exploit others toward my own end", and 12, "I tend to expect special favors from 645 others" double-load on two separate factors. Items 4, 5, and 7 have somewhat varying loadings 646 for males and females.

647

648 Table 5. Item Response Theory Analysis of the Dirty Dozen.

649 Note. Items are ranked according to item's ability to discriminate (a) levels of the latent trait (the 650 core of the Dark Triad) and are numbered according to their positions in the original 651 questionnaire (DD Machiavellianism, 1-4, DD psychopathy, 5-8, and DD narcissism, 9-12). b16526 reports the item difficulties, reflecting the threshold level $(-3$ to $+3 \mathrm{SD})$ of the latent trait 653 necessary to have at least a 50\% chance of endorsing the next scale-steps. 654

655 Figure 1. Bi-factor model of Dirty Dozen. $N=3,698 . \mathrm{NFI}=.98, \mathrm{CFI}=.98, \mathrm{RMSEA}=.05$. 656 
657 Figure 2. Frequency distributions showing the bi-modality of the three Dirty Dozen Dark Triad 658 traits. $N=3,698$. The numbers on the y-axis represent the proportion of replies for each Likert659 category (1-7) on the x-axis. For instance, $47 \%$ of total replies on DD psychopathy items were 660 placed on the lowest option (1) "strongly disagree", which depicts the skewness in response 661 pattern.

662 Figure 3. Total Information Curve on the latent core of the Dark Triad Dirty Dozen. Overall, the 663 Dirty Dozen instrument delivers the most predictive value with persons with average and high 664 Dark Triad traits (theta $>-0.5)$.

665

666 Figure 4. Scale Information Curves depicting the information content in each respective sub 667 factor.

668

669 Figure 5. Item Information Curves for each of the 12 items of the Dirty Dozen. Note that item 1 670 (Manipulate) and 4 (Exploit) deliver the most information on the latent Dark Triad (labeled 671 theta). Item 8 (Cynicism) delivers the least information. Furthermore, the three first items on 672 narcissism (9-11) don't deliver much predictive information (flat curves, cf. earlier CFA bi673 factor model) to the overall Dark Triad trait - However, an IRT with only the narcissism items 674 confirms that these predict the latent trait (theta, i.e., narcissism) very satisfactorily (cf. earlier 675 CFA hierarchical model).

676 


\section{Table $\mathbf{1}$ (on next page)}

Table 1.

Jonason's Dark Triad Dirty Dozen Scale: traits, item numbers, statements, and key word in each one of the statements. Note. From Jonason, P. K., \& Webster, G. D. (2010). The Dirty Dozen: A concise measure of the Dark Triad. Psychological Assessment, 22, 420-432. 
1 Table 1. Jonason's Dark Triad Dirty Dozen Scale: traits, item numbers, statements, and key word

2 in each one of the statements.

\begin{tabular}{|c|c|c|c|}
\hline Trait & Item No. & Statement & Key Word \\
\hline \multirow{4}{*}{ 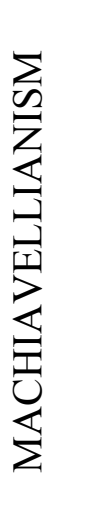 } & 1 & I tend to manipulate others to get my way. & Manipulate \\
\hline & 2 & I have used deceit or lied to get my way. & Deceit \\
\hline & 3 & I have use flattery to get my way. & Flatter \\
\hline & 4 & I tend to exploit others towards my own end. & Exploit \\
\hline \multirow{4}{*}{ 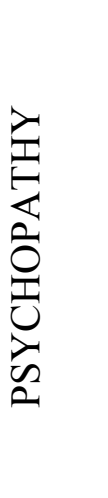 } & 5 & I tend to lack remorse. & Remorse \\
\hline & 6 & I tend to be unconcerned with the morality of my actions. & Amoral \\
\hline & 7 & I tend to be callous or insensitive. & Callous \\
\hline & 8 & I tend to be cynical. & Cynical \\
\hline \multirow{4}{*}{ 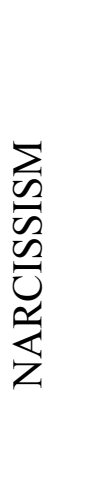 } & 9 & I tend to want others to admire me. & Admire \\
\hline & 10 & I tend to want others to pay attention to me. & Attend \\
\hline & 11 & I tend to seek prestige or status. & Status \\
\hline & 12 & I tend to expect special favors from others. & Favors \\
\hline
\end{tabular}

3 Note. Adapted from Jonason, P. K., \& Webster, G. D. (2010). The Dirty Dozen: A concise

4 measure of the Dark Triad. Psychological Assessment, 22, 420-432. 


\section{Table 2 (on next page)}

Table 2.

Descriptive Analysis of the Dark Triad traits as measured by the Dark Triad Dirty Dozen. Note. $N=3,698 ; N_{\text {males }}=1726 ; N_{\text {females }}=1972 ;{ }^{+}$composite score of the three dark traits. 
1 Table 2. Descriptive Analysis of the Dark Triad traits as measured by the Dark Triad Dirty Dozen.

\begin{tabular}{lccccccccccccc}
\hline & $M$ & $S D$ & $\alpha$ & Skewness & Kurtosis & $M_{\text {male }}$ & $S D_{\text {male }}$ & $\alpha_{\text {male }}$ & $M_{\text {female }}$ & $S D_{\text {female }}$ & $\alpha_{\text {female }}$ \\
1 DD Machiavellianism & 3.00 & 1.41 & 0.80 & 0.38 & -0.66 & 3.23 & 1.45 & .84 & 2.79 & 1.35 & .85 \\
2 DD Psychopathy & 2.42 & 1.26 & 0.76 & 0.95 & 0.43 & 2.74 & 1.30 & .81 & 2.13 & 1.14 & .79 \\
3 DD Narcissism & 3.55 & 1.44 & 0.81 & -0.15 & -0.81 & 3.71 & 1.43 & .75 & 3.41 & 1.44 & .74 \\
4 Dark Triad & 2.99 & 1.08 & 0.85 & 0.26 & -0.27 & 3.23 & 1.08 & .80 & 2.78 & 1.04 & .81
\end{tabular}

2 Note. $N=3,698 ; N_{\text {males }}=1726 ; N_{\text {females }}=1972 ;{ }^{+}$composite score of the three dark traits. 


\section{Table 3 (on next page)}

Table 3.

Convergent analysis (Persons' $r$ ) of the Dark Triad Dirty Dozen traits and the dark traits and Extraversion, and Neuroticism as measured by the Mach-IV, Eysenck's Personality Questionnaire Revised, and the Neuroticism Personality Inventory. Note. $N=500$. All $r$ coefficients $>.12$ are significant at $p<.01$. + Summarized composite score of the three dark traits. Yellow fields: intra-relationships within the Dark Triad Dirty Dozen traits and the Dark Triad composite. Blue fields: intra-relationships within the Dark Triad traits measured by the single instruments (i.e., MACH-IV, Eysenck's Personality Questionnaire Revised, and the Narcissism Personality Inventory). Green fields: relationships between corresponding dark traits measured using the Dirty Dozen scale and the single instruments. Black fields: relationships between dark traits as measured by the Dirty Dozen and Neuroticism and Extraversion. Grey fields: relationships between dark traits as measured by the single instruments and Neuroticism and Extraversion. 
1 Table 3. Convergent analysis (Persons' r) of the Dark Triad Dirty Dozen traits and the dark traits and Extraversion, and Neuroticism

2 as measured by the Mach-IV, Eysenck's Personality Questionnaire Revised, and the Neuroticism Personality Inventory.

\begin{tabular}{|c|c|c|c|c|c|c|c|c|c|c|}
\hline & 1 & 2 & 3 & 4 & 5 & 6 & 7 & 8 & 9 & Item 4: \\
\hline 1 DD Machiavellianism & - & .58 & .50 & .88 & .49 & .27 & .37 & .26 & .10 & .80 \\
\hline 2 DD Psychopathy & & - & .27 & .75 & .57 & .41 & .30 & .25 & -.11 & .60 \\
\hline 3 DD Narcissism & & & - & .76 & .22 & .09 & .47 & .20 & .25 & .43 \\
\hline 4 Dark Triad $^{+}$ & & & & - & .53 & .31 & .49 & .30 & .11 & .77 \\
\hline 5 Machiavellianism & & & & & - & .40 & .34 & .28 & -.06 & .50 \\
\hline 6 Psychopathy & & & & & & - & .35 & .05 & .05 & .30 \\
\hline 7 Narcissism & & & & & & & - & -.07 & .40 & .40 \\
\hline 8 Neuroticism & & & & & & & & - & -.24 & .18 \\
\hline 9 Extraversion & & & & & & & & & - & .09 \\
\hline Item 4: Exploit & & & & & & & & & & - \\
\hline
\end{tabular}

3 Note. $N=500$. All $r$ coefficients $>.12$ are significant at $p<.01 .{ }^{+}$Summarized composite score of the three dark traits.

4 Yellow fields: intra-relationships within the Dark Triad Dirty Dozen traits and the Dark Triad composite.

5 Blue fields: intra-relationships within the Dark Triad traits measured by the single instruments (i.e., MACH-IV, Eysenck's Personality

6 Questionnaire Revised, and the Narcissism Personality Inventory).

7 Green fields: relationships between corresponding dark traits measured using the Dirty Dozen scale and the single instruments.

8 Black fields: relationships between dark traits as measured by the Dirty Dozen and Neuroticism and Extraversion.

9 Grey fields: relationships between dark traits as measured by the single instruments and Neuroticism and Extraversion. 


\section{Table 4 (on next page)}

Table 4.

Item Response Theory Rank and Exploratory Factor Analysis of Dirty Dozen Items. Note. * $=$ Potentially conflicting items in regards to double-loadings. Bold figures $=$ Loadings according to three-factor Dark Triad theory. Cursive figures = Loadings deviating from three-factor Dark Triad theory (> .50). Item 8, underscored, "I tend to be cynical" does not load well enough on the psychopathy-factor and deviates from theory by aligning also with Machiavellianism (especially for females). Items 1 , "I tend to manipulate others to get my way", 4, "I tend to exploit others toward my own end", and 12, "I tend to expect special favors from others" double-load on two separate factors. Items 4, 5, and 7 have somewhat varying loadings for males and females. 
1 Table 4. Item Response Theory Rank and Exploratory Factor Analysis of Dirty Dozen Items.

\begin{tabular}{|c|c|c|c|c|c|c|c|}
\hline & \multicolumn{4}{|c|}{ Males } & \multicolumn{3}{|c|}{ Females } \\
\hline & Info & Machiavellianism & Psychopathy & Narcissism & Machiavellianism & Psychopathy & Narcissism \\
\hline & rank & & & & & & \\
\hline 1 Manipulate* & 2 & .81 & .54 & .34 & .77 & .50 & .38 \\
\hline 2 Deceit & 3 & .73 & .46 & .30 & .76 & .40 & .35 \\
\hline 3 Flatter & 8 & .59 & .27 & .44 & .60 & .26 & .43 \\
\hline 4 Exploit* & 1 & .78 & .60 & .36 & .70 & .60 & .35 \\
\hline 5 Remorse & 5 & .44 & .78 & .08 & .42 & .84 & .17 \\
\hline 6 Amoral & 4 & .46 & .72 & .15 & .41 & .76 & .16 \\
\hline 7 Callous* & 6 & .47 & .77 & .13 & .50 & .70 & .20 \\
\hline$\underline{8 \text { Cynical* }}$ & 11 & .36 & $\underline{.40}$ & .14 & .45 & $\underline{.42}$ & .25 \\
\hline 9 Admire & 10 & .35 & .09 & .81 & .40 & .11 & .81 \\
\hline 10 Attend & 12 & .33 & .08 & .78 & .34 & .11 & .80 \\
\hline 11 Status & 9 & .38 & .16 & .73 & .41 & .23 & .73 \\
\hline 12 Favors* & 7 & .52 & .36 & .55 & .51 & .43 & .57 \\
\hline
\end{tabular}

2 Note. $^{*}=$ Potentially conflicting items in regards to double-loadings. Bold figures $=$ Loadings

3 according to three-factor Dark Triad theory. Cursive figures $=$ Loadings deviating from three-

4 factor Dark Triad theory $(>.50)$. Item 8 , underscored, "I tend to be cynical" does not load well 5 enough on the psychopathy-factor and deviates from theory by aligning also with 6 Machiavellianism (especially for females). Items 1, "I tend to manipulate others to get my way", 74 , "I tend to exploit others toward my own end", and 12, "I tend to expect special favors from 8 others" double-load on two separate factors. Items 4, 5, and 7 have somewhat varying loadings 9 for males and females. 


\section{Table 5 (on next page)}

Table 5.

Item Response Theory Analysis of the Dirty Dozen. Note. Items are ranked according to item's ability to discriminate (a) levels of the latent trait (the core of the Dark Triad) and are numbered according to their positions in the original questionnaire (DD Machiavellianism, 14, DD psychopathy, 5-8, and DD narcissism, 9-12). b1-6 reports the item difficulties, reflecting the threshold level $(-3$ to $+3 \mathrm{SD})$ of the latent trait necessary to have at least a $50 \%$ chance of endorsing the next scale-steps. 
1 Table 5. Item Response Theory Analysis of the Dirty Dozen.

\begin{tabular}{|c|c|c|c|c|c|c|c|}
\hline Item & $a$ & $b_{1}$ & $b_{2}$ & $b_{3}$ & $b_{4}$ & $b_{5}$ & $b_{6}$ \\
\hline 4 Exploit & 3.33 & -0.03 & 0.63 & 0.97 & 1.31 & 1.99 & 2.58 \\
\hline 1 Manipulate & 2.73 & -0.24 & 0.42 & 0.75 & 0.94 & 1.78 & 2.54 \\
\hline 2 Deceit & 1.96 & -0.71 & -0.07 & 0.27 & 0.44 & 1.24 & 2.35 \\
\hline 6 Amoral & 1.91 & 0.36 & 1.11 & 1.56 & 1.87 & 2.44 & 3.14 \\
\hline 5 Remorse & 1.84 & 0.25 & 1.00 & 1.36 & 1.68 & 2.29 & 3.10 \\
\hline 7 Callous & 1.82 & -0.03 & 0.75 & 1.15 & 1.45 & 2.18 & 3.05 \\
\hline 12 Favors & 1.71 & -0.47 & 0.42 & 0.82 & 1.37 & 2.21 & 3.35 \\
\hline 3 Flatter & 1.41 & -1.43 & -0.79 & -0.35 & -0.07 & 1.00 & 2.46 \\
\hline 11 Status & 1.19 & -1.23 & -0.45 & 0.02 & 0.52 & 1.59 & 2.76 \\
\hline 8 Cynical & 1.07 & -1.13 & -0.41 & 0.05 & 0.43 & 1.41 & 2.77 \\
\hline 9 Admire & 1.02 & -2.12 & -1.38 & -0.89 & -0.18 & 1.07 & 2.83 \\
\hline 10 Attend & 0.91 & -1.99 & -1.12 & -0.54 & 0.21 & 1.72 & 3.75 \\
\hline
\end{tabular}

2 Note. Items are ranked according to item's ability to discriminate $(a)$ levels of the latent trait (the 3 core of the Dark Triad) and are numbered according to their positions in the original 4 questionnaire (DD Machiavellianism, 1-4, DD psychopathy, 5-8, and DD narcissism, 9-12). $b_{1-6}$ 5 reports the item difficulties, reflecting the threshold level $(-3$ to $+3 \mathrm{SD})$ of the latent trait 6 necessary to have at least a $50 \%$ chance of endorsing the next scale-steps. 
1

Bi-factor model of Dirty Dozen. $N=3,698 . \mathrm{NFI}=.98, \mathrm{CFI}=.98, \mathrm{RMSEA}=.05$.

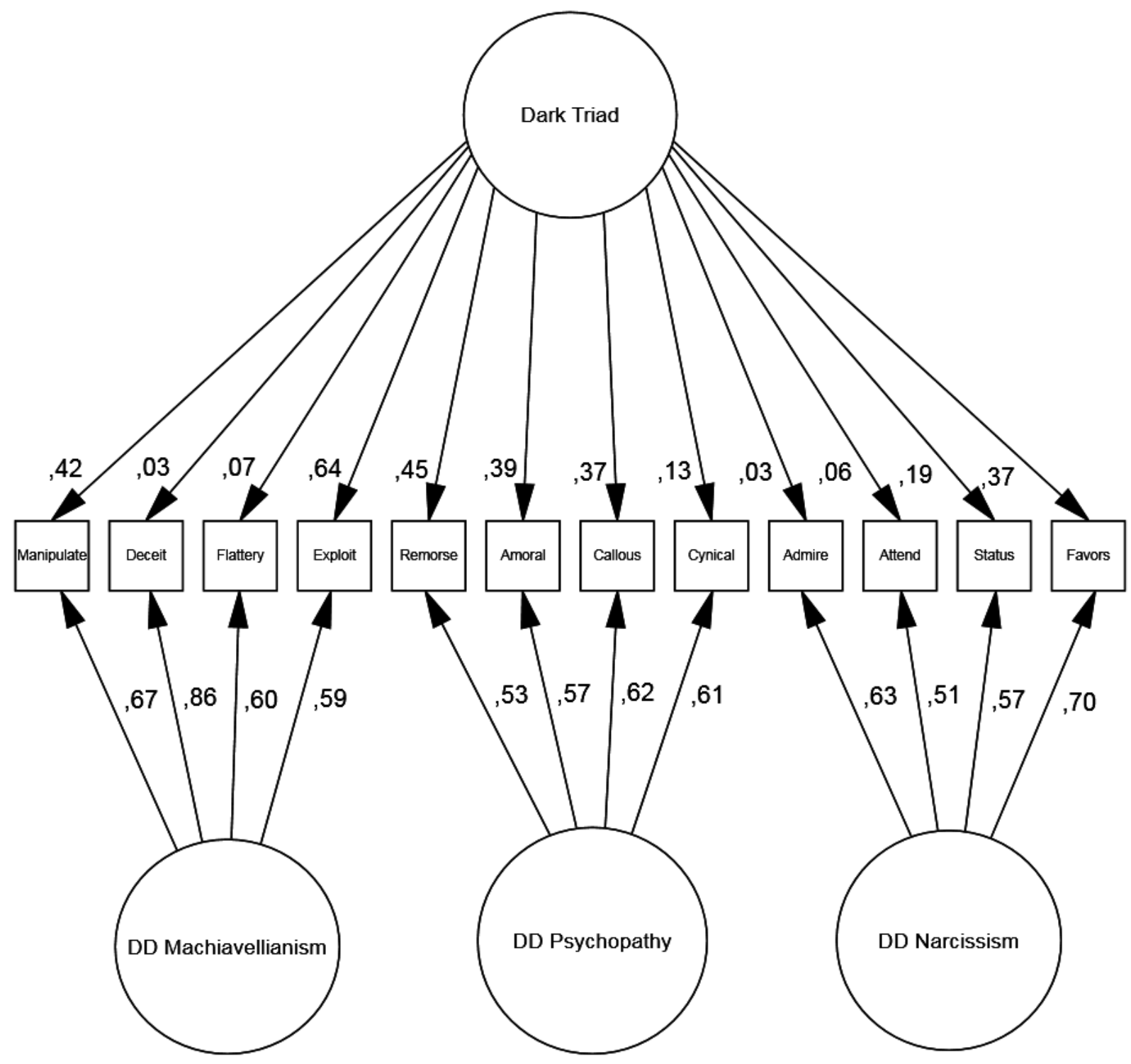


2

Frequency distributions showing the bi-modality of the three Dirty Dozen Dark Triad traits. $N=3,698$. The numbers on the $y$-axis represent the proportion of replies for each Likert-category (1-7) on the x-axis. For instance, $47 \%$ of total replies on

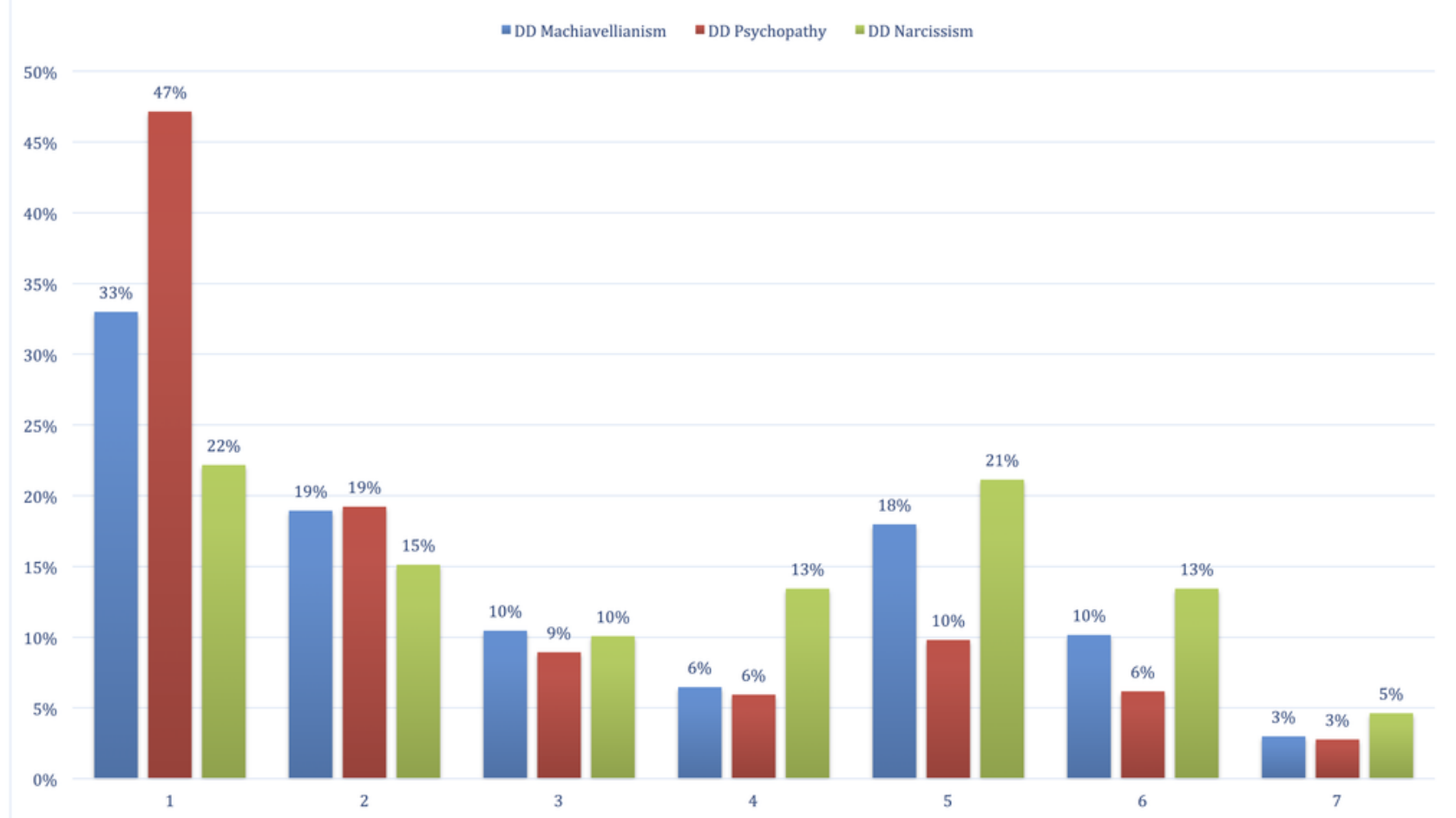


3

Total Information Curve on the latent core of the Dark Triad Dirty Dozen. Overall, the Dirty Dozen instrument delivers the most predictive value with persons with average and high Dark Triad traits (theta $>-0.5$ ).

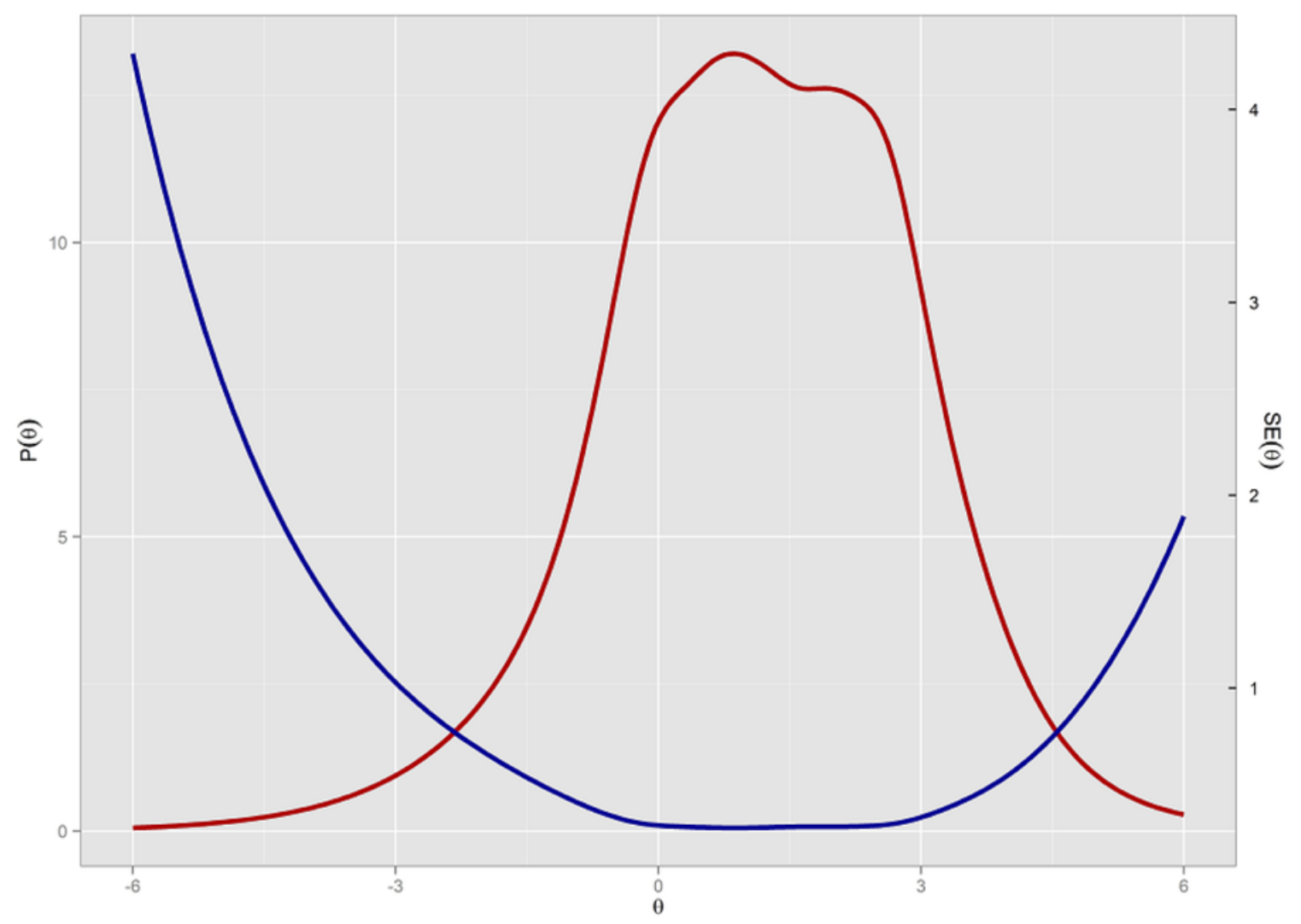


4

Scale Information Curves depicting the information content in each respective sub factor.

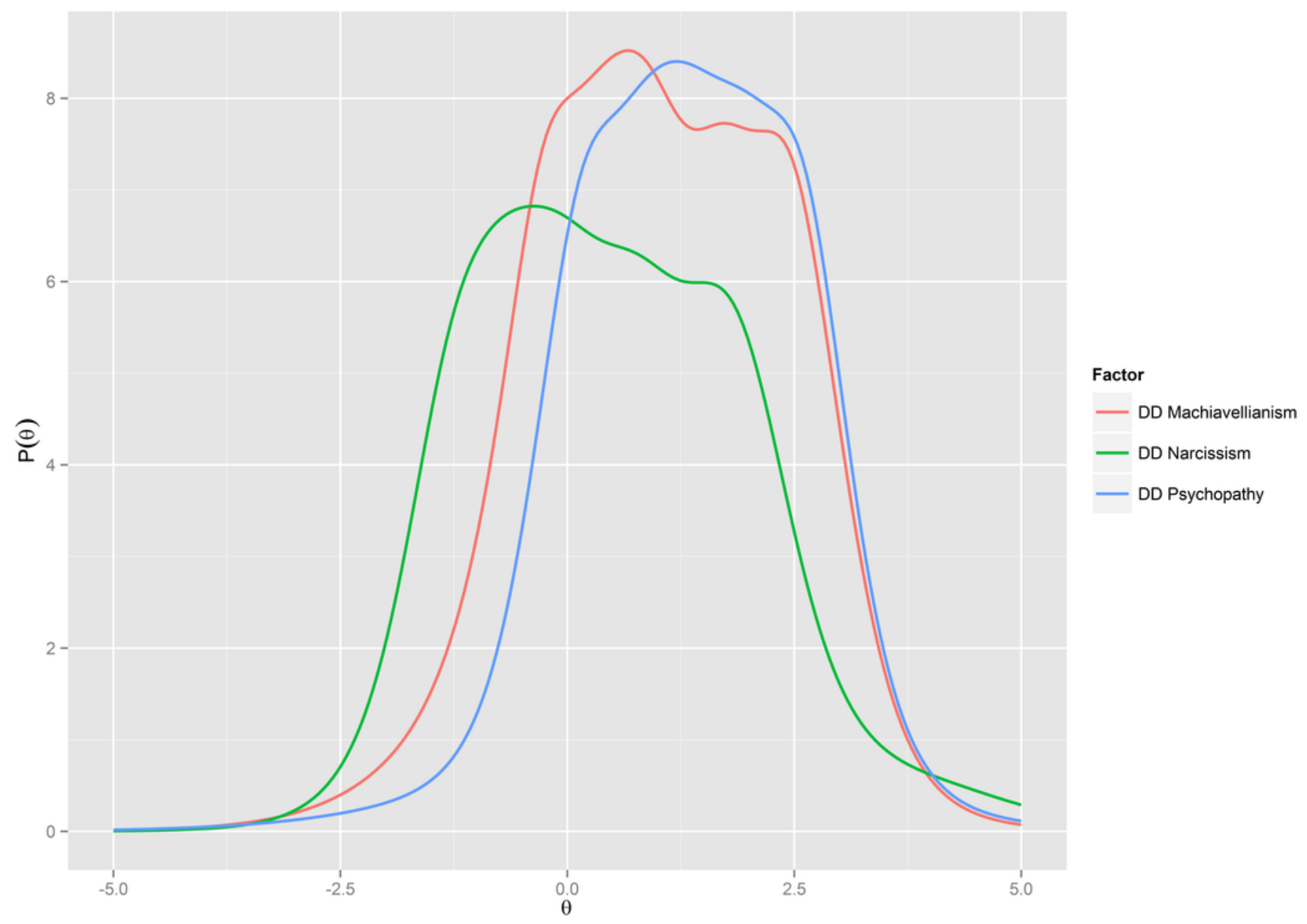


5

Item Information Curves for each of the 12 items of the Dirty Dozen. Note that item 1 (Manipulate) and 4 (Exploit) deliver the most information on the latent Dark Triad (labeled theta). Item 8 (Cynicism) delivers the least information. Furthermore,
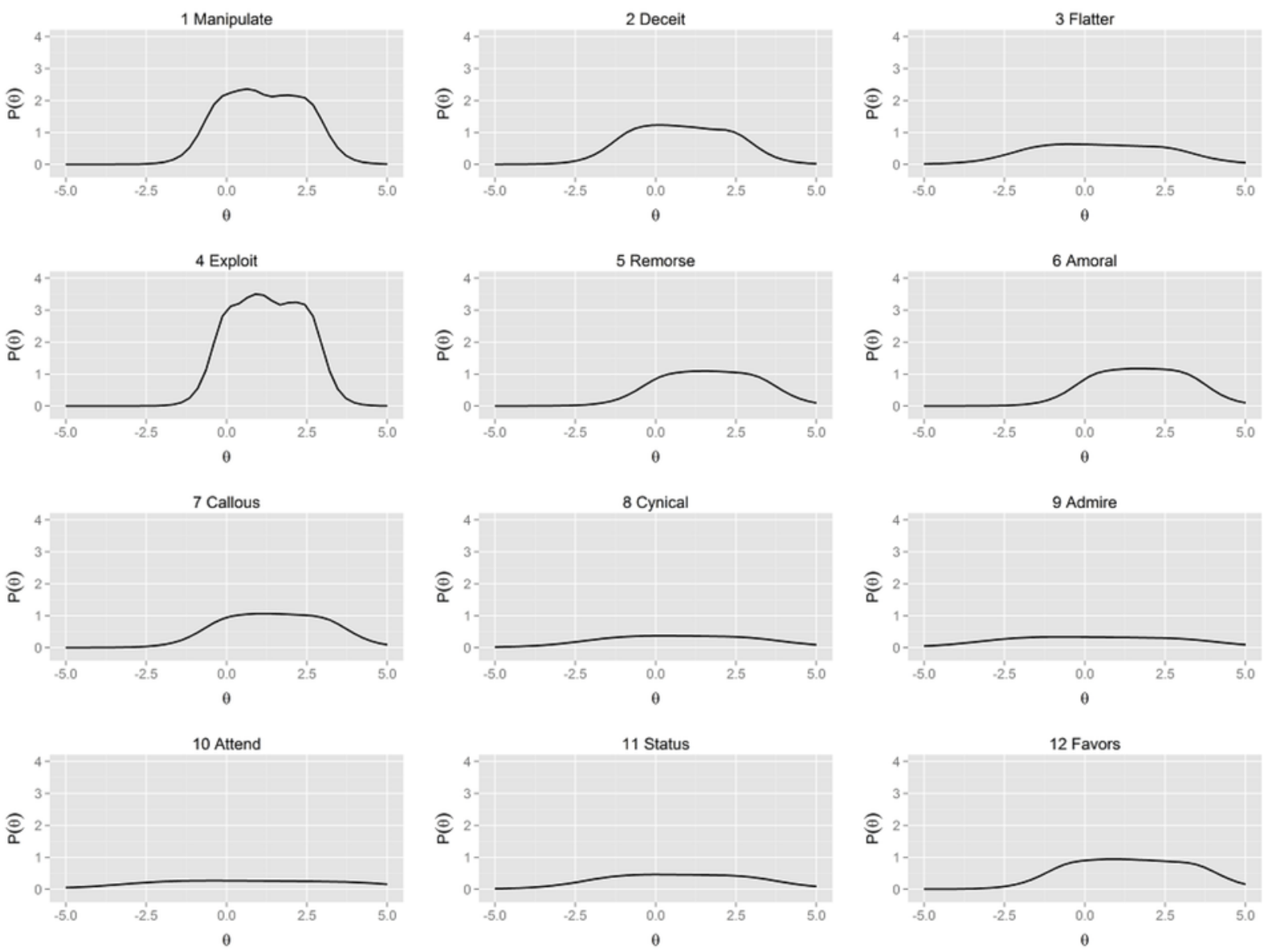